\title{
THE EFFECT OF POSTURE ON THE ROLE OF PECTORALIS MAJOR AND LATISSIMUS DORSI MUSCLES IN EXPIRATION IN TETRAPLEGIA
}

\section{Poobalam Gounden PhD Physiotherapy *}

\section{SUMMARY}

This study was designed to examine the effect of posture on forced expiration as reflected in phasic electromyographic activity in accessory expiratory muscles in tetraplegic subjects with complete lesions between the fifth and eight cervical segments. In order to determine the effect of posture on the action of the clavicular head of the pectoralis major muscle and the latissimus dorsi muscle during forced expiration, the subjects were studied in two test positions, support sitting and supine lying.

Electromyographic examination of the above mentioned muscles in eight tetraplegic subjects showed changes in electrical activity in the clavicular portion of the pectoralis major muscle when the subjects were studied in the supine position. Four out of eight subjects showed evidence of an increase in EMG activity in the supine lying position. When the muscle was tested with the patient in the supported sitting position it failed to demonstrate a significant increase in electromyographic activity during forced expiration.

We concluded therefore that the role of the clavicular portion of the pectoralis major muscle during expiration in tetraplegia is posture dependent. These findings have important therapeutic implications: specific training programmes to increase the strength and endurance of this muscle should be conducted with the subject in the correct position. The action of the latissimus dorsi muscle was not significantly influenced by the postural changes during forced expiration.

\section{INTRODUCTION}

Tetraplegics with traumatic transection of the spinal cord be tween the fifth and eight cervical segments lose their intercostal and. abdominal contribution to respiration. The resultant neuromuscular respiratory insufficiency exposes the patient to serious respiratory complications such as retention of secretions, lung collapse and pneumonia ${ }^{1,23,4,5}$.

A distinctive feature of the respiratory dysfunction in tetraplegics is the marked reduction in expiratory force because of paralysis of all the known muscles of expiration. This causes severe impairment of the patient's ability to cough, an important mechanism in shifting secretions.

Several studies discuss the physiological and pathological sequelae of ventilatory muscle paralysis in tetraplegia but there is very little known about their mechanism of expiration ${ }^{6,7,8,9,10}$. Goldman et al demonstrated tonic electromyographic (EMG) activity in the abdominal muscles while normal phasic inspiratory activity was present in the diaphragm. This was due to movement in the abdominal wall caused by a stretch reflex mediated at the spinal cord. This was present only during inspiration and therefore had no effect on the expiratory phase of respiration ${ }^{11}$.

De Troyer at al recently detailed the mechanism of forced expiration in tetraplegics with lesions below the fifth cervical segment when they studied the action of the clavicular head of the pectoralis major and latissimus dorsi muscles ${ }^{9}$. Increased electromyographic activity in the clavicular head of the pectoralis major muscle occurred synchronously with forced expiration with a concomitant reduction in the anterior-posterior diameter of the upper rib cage. Similar electrical activity was recorded for latissimus dorsi muscles during forced expiration ${ }^{9}$. Strengthening the accessory muscles of expiration could probably serve an important prophylactic modality in the overall management of pulmonary problems as encountered with the lesions described above ${ }^{13}$. Carter highlights the importance of preventative therapy. "Certainly there are few, if any, areas elsewhere in the field of medicine that require treatment prior to the onset of pathology as does the respiratory muscle weakness in spinal cord injury"2.

In order to achieve optimal training results the patient should be exercised in a position which would ensure maximal recruitment of the muscle fibres. The selection of suitable training positions is important because it has been shown that the accessory inspiratory muscle performance in tetraplegic subjects is posture dependent ${ }^{12}$.

Estenne found an increase in the amplitude of inspiratory EMG activity when examination position of patients was changed from supported sitting to supine ${ }^{12}$.

Although the influence of posture on accessory inspiratory muscle action in tetraplegics has been investigated electromyographically by de Troyer, no systematic studies of the effect of posture on accessory expiratory muscle performance have been carried out ${ }^{9}$. Therefore, this study was designed to examine the effect of posture on forced expiration as demonstrated by electromyographic activity in the clavicular part of the pectoralis major muscle and latissimus dorsi muscle in order to identify the optimal training position.

\section{METHOD}

\section{Subjects}

We studied eight randomly selected tetraplegics with functionally complete transection of the cervical cord as evidence by clinical examination. All had suffered traumatic fracture dislocation of the cervical spine between the fifth and eighth cervical vertebrae as evidence by spinal radiographs. The post-injury period in all eight patients was least four months:

A preliminary inclusion interview eliminated subjects with respiratory disease as evidenced by lung radiographs and chest physical examination.

This study population consisted of seven males and one female with ages ranging from eighteen to forty-five years, as shown in Table I. An informed consent was obtained from all the patients. The study was reviewed and approved by the Ethics Committee of the Faculty of Medicine at the University of Natal.

\section{TABLE I:DEMOGRAPHY OF PATIENTS}

\begin{tabular}{|c|c|c|c|}
\hline PATIENT & AGE & LEVEL OF INJURY & POST-INJURY PERIOD \\
\hline 1 & 27 & C6 & 6 months \\
\hline 2 & 24 & C6 & 4 years \\
\hline 3 & 25 & C6 & 1 year \\
\hline 4 & 45 & C6 & 7 months \\
\hline 5 & 26 & C6 & 4 years \\
\hline 6 & 30 & C6,7 & 3 years \\
\hline 7 & 38 & $C 7$ & 3 years \\
\hline 8 & 18 & $C 7$ & 4 months \\
\hline \hline
\end{tabular}




\section{WHEN MUCOCILIARY CLEARANCE IS A STICKY PROBLEM}

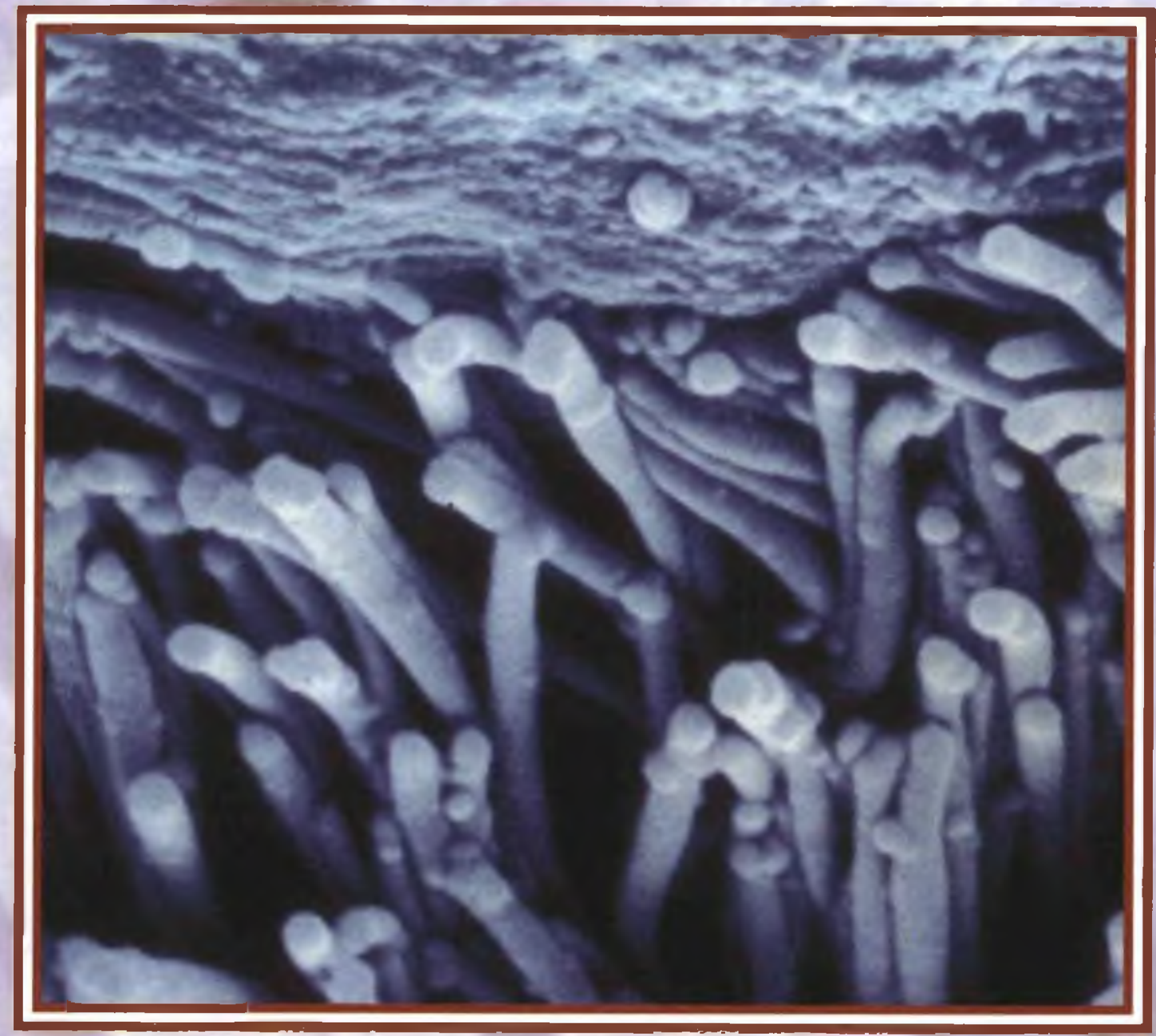

Every physiotherapist knows that effective clearance of the bronchial passages is virtually impossible without the help of their staunchest ally - the cilia. But ciliary activity is inhibited by the thick tenacious mucus associated with bronchial disease. And, to make matters worse, the microbes associated with bacterial and viral infections can release certain compounds which slow ciliary beating ${ }^{(1)}$.

Luckily there's Bisolvon 0,2 Solution - a proven enhancer of mucociliary clearance.
REDUCES MUCUS VISCOSITY ${ }^{(2,3,4)}$

- Interferes with the production of Acid Mucopolysaccharide molecules in the goblet cells

- Helps break down existing mucus by increasing lysosome secretion $^{(4)}$

\section{FACILITATES ANTIBIOTIC ACTION}

Oral Bromhexine significantly increases the penetration of various antibiotics into the bronchial secretions $^{(5,6)}$ 


\section{TRUST THE PROVEN SOLUTION TO SOLVE IT}

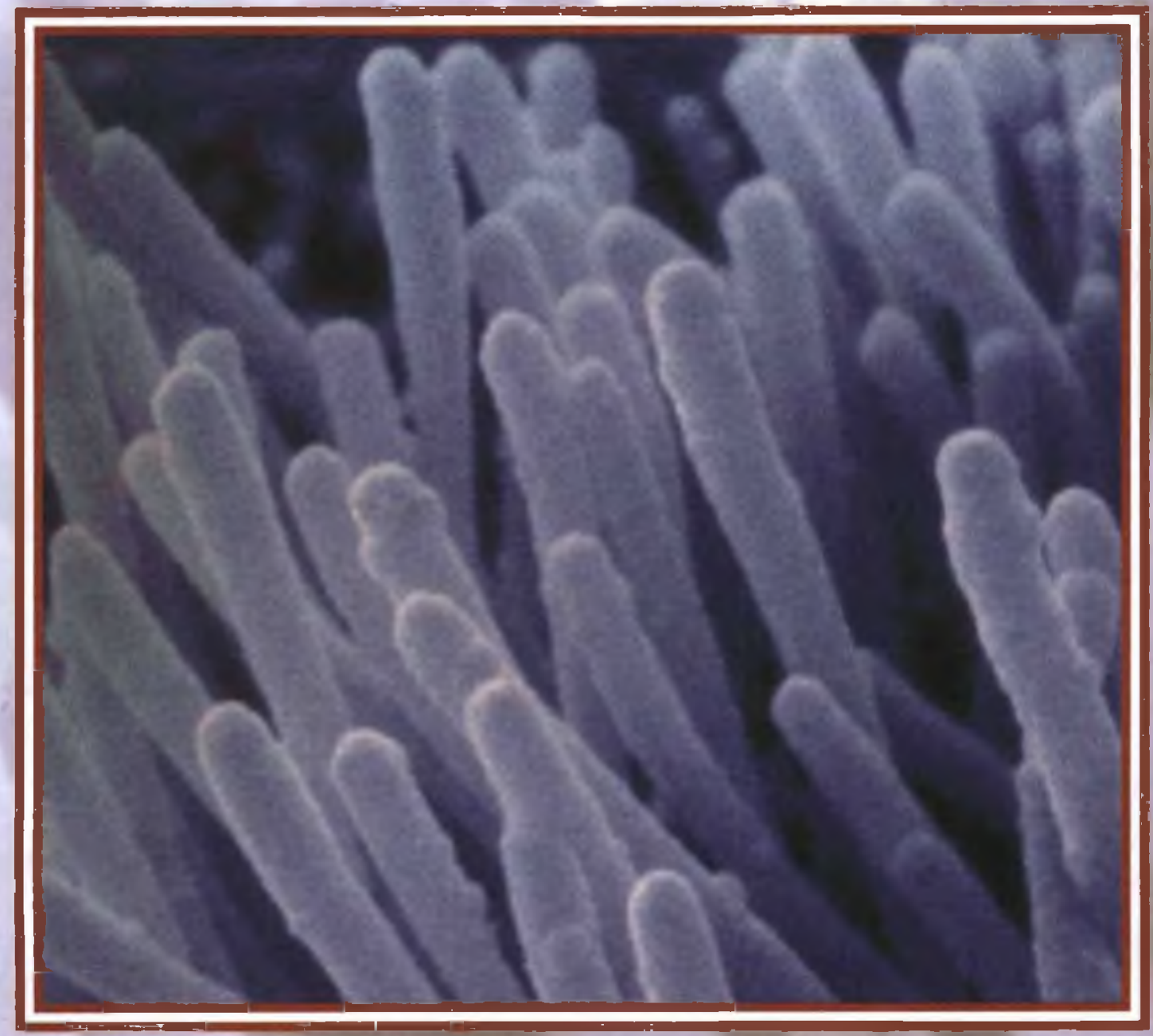

Two very good reasons why you shouldn't be sticky about using Bisolvon 0,2\% Solution for your patients.

THE PROVEN SOLUTION TO A STICKY PROBLEM

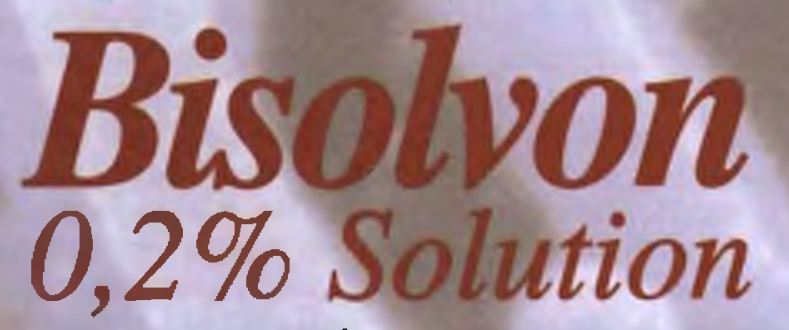
Bromhexine $\mathrm{HCl}$

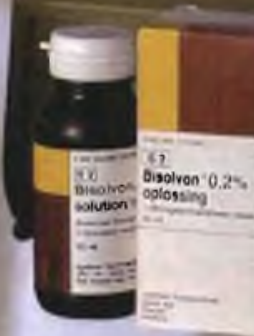

\section{.}

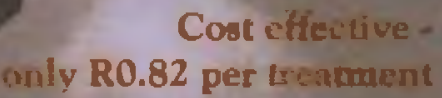

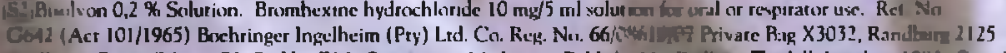

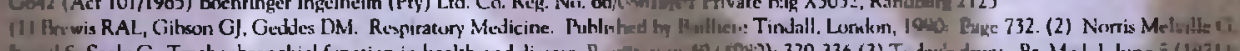

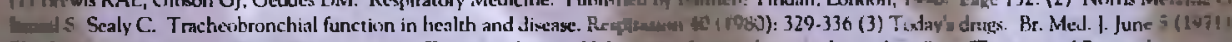

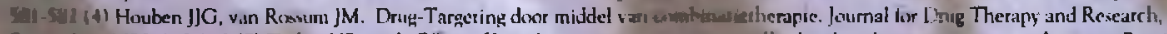

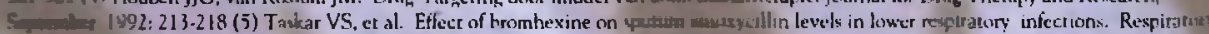

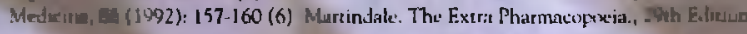




\section{Electromyographic examination}

The electrical activity of a specific muscle was studied by inserting a recording needle electrode directly into the muscle. The bioelectric potential that was recorded by this electrode was amplified and then displayed on a cathode ray oscilloscope for visual analysis and fed through a loudspeaker system so that it could be monitored acoustically. A permanent photographic record of the oscilloscope trace can be made, if desired.

Aspecialist neurologist from the Department of Neurology at the Medical Faculty of the University of Natal assisted with the electromyographic examinations and was responsible for the insertion of the needle electrode. Each patient was examined in two test positions, ie sitting (with support) and in supine. The clavicular head of the pectoralis major muscle and latissimus dorsi muscle were examined with the aid of the Disa 2000 EMG machine. With the patient in the supine position and the upper limb on the side of the examination adducted and internally rotated, the clavicular head of the pectoralis major muscle was identified.

Using a sterile technique and with the muscle relaxed, a concentric needle electrode was inserted into the belly of the muscle approximately two centimeters below the mid-position of the clavicle. The latissimus dorsi muscle was studied with the needle electrode inserted in the posterior axillary fold. Recordings of EMG activity were obtained from the study positions during both tidal breathing and forced expiration.

The study design required three EMG recordings from each muscle:

- The first recording presented EMG activity of the muscle while the patient was at rest tidal breathing in the supine position.

- The second showed EMG activity while the patient was in the supported sitting position and performing forced expiration with the aid of the PFLEX trainer. This training device is an effective and economical apparatus designed to offer resistance to either inspiratory or expiratory air-flow.

- The third recording showed EMG activity in the accessory muscles while the patient was performing forced expiration with the aid of the PFLEX trainer in the supine position.

The three recordings from each muscle were arranged in panels one below the other according to the above order (Fig 1-3). The amplitude and "fullness of the interference pattern", as recorded by the EMG, constituted the criteria for determining the optimal functioning positions ${ }^{14}$.

\section{RESULTS}

The clavicular head of the pectoralis major muscle showed dis. tinct phasic activity in all eight patients during forced expiration. Figure 1 shows the pattern of phasic EMG activity in the clavicular head of the pectoralis major muscle during forced expiratory in patient number four.

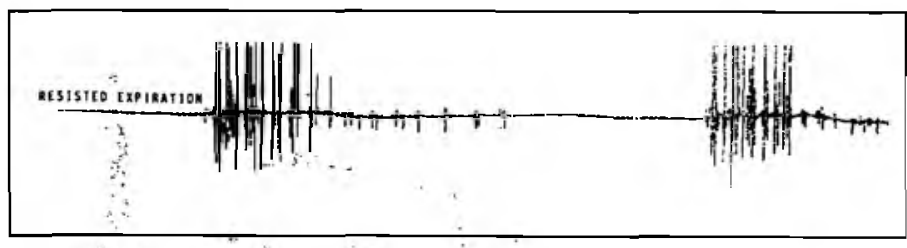

Figure 1: Phasic motor unit activity for clavicluar head of Pectoralis Major ouring forced expiration with the subject in supine

Four patients showed greater electrical activity in this muscle when studied in the supine position:

Figures 2 and 3 show the representative changes in phasic EMG activity when the positions of three patients were changed from the sitting to the supine lying position. This activity was not present during relaxed tidal breathing, but became apparent as ventilation increased. The increase in phasic EMG activity in the supine position occurred simultaneously with the forced expiratory phase and tapered off abruptly at the end of the expiratory effort.

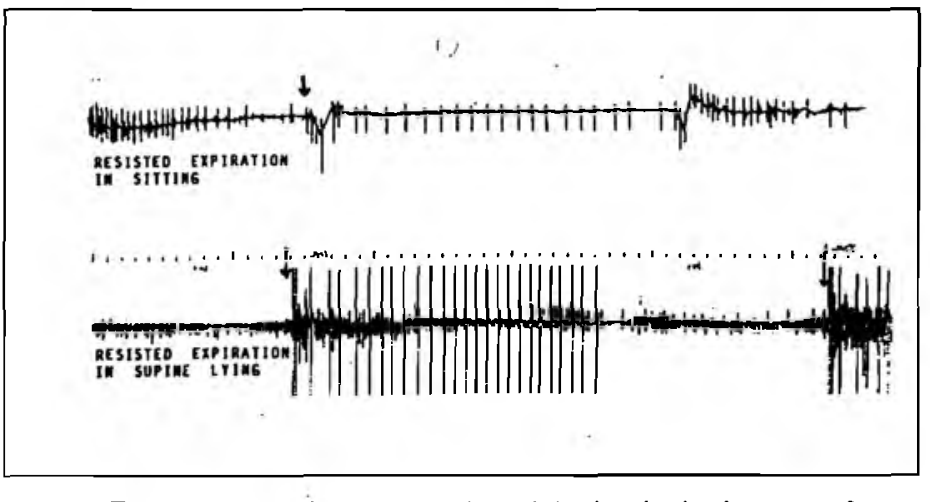

Figure 2: Phasic motor unit activity in clavicular part of Pectoralis Major during forced resisted expiration with the subject in sitting and in supine

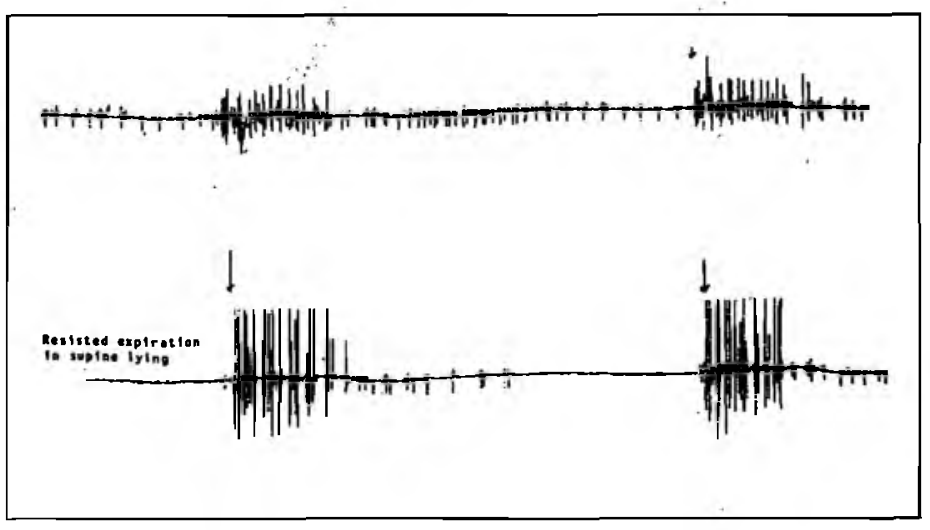

Figure 3: Phasic motor unit activity in calvicular part of Pectoralis Major during forced resisted expiration with the subject in sitting and in lying

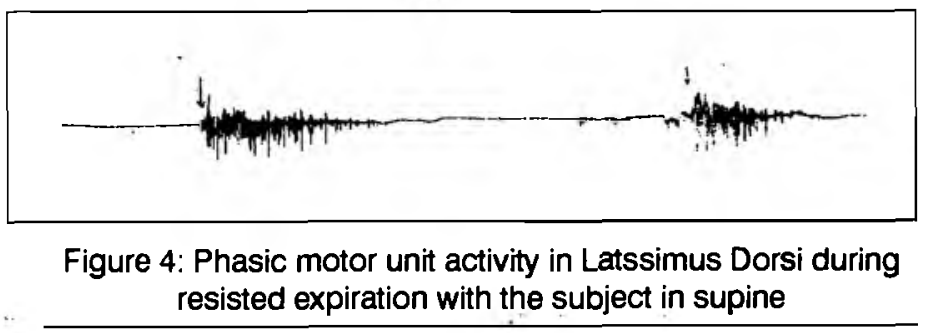

The analysis of the EMG recordings from the latissimus dorsi muscle showed distinct phasic activity in five patients. The changes in electrical activity occurred simultaneously with forced expiration as shown in Figure 4. Electromyographic activity in latissimus dorsi muscle was not affected by changes in posture. EMG recordings from latissimus dorsi in the remaining three patients showed inconsistency in phasic activity.

\section{DISCUSSION}

Traumatic injuries of the cervical spine constitute fifty per cent of spinal injuries ${ }^{15,16,17}$. The resultant neurological deficit unaccompanied by immediate fatality, results in tremendous morbidity and consequent later mortality 2,5 .

The principal cause of death is respiratory insufficiency, secondary to aspiration pneumonia. If accessory ventilatory muscles could be recruited for expiration this may help alleviate the problem. De Troyer noted the recruitment of pectoralis major muscle and latissimus dorsi muscle during forced expiration ${ }^{9}$. Additionally, the clavicular head of the pectoralis major muscle receives its nerve fibres from the (fifth, sixth and seventh) cervical segments unlike the sternocostal portion which would be paralysed, due to its innervation at a lower level. 
The influence of posture on the expiratory force of the clavicular portion of the pectoralis major muscle has not been studied. De Troyer $e t$ al only studied patients in the supported sitting position?. Our study has shown that, in four out of eight subjects, a significant increase in EMG activity occurred in the supine position compared to the readings obtained in the support sitting position.

We recommend that in patients with tetraplegia, an accurate assessment of ventilatory muscle dysfunction be undertaken, if necessary, with electromyography. When a decision for ventilatory muscle training is made then the correct posture for maximum benefit of the clavicular portion of the pectoralis major muscle needs to be determined. Thereafter ventilatory muscle training should employ this position to ensure the best results.

\section{CONCLUSION}

The supine lying position was associated with the ability to generate greater changes in EMG activity in the clavicular portion of the pectoralis major muscle during forced expiration in four tetraplegic subjects. These findings stress the need for the selection of correct starting position for accessory expiratory muscle training in tetraplegia.

\section{References}

1. McCagg C. Post-operative management and acute rehabilitation of patients with spinal cord injuries. Orthop Clin North Am 1986;17(1):171-182.

2. Carter RE. Respiratory aspects of spinal cord injury management. Paraplegia 1987;25:262-266.

3. Hultgren A, Fugl-Meyer AR, Jonasson E, et al. Ventilatory dysfunction and respiratory rehabilitation in post traumatic quadriplegia. Eur $J$ Resp Dis 1980;61:347-356.

4. Axel R, Fugl-Meyer AR, Grimby G. Respiration in tetraplegia and hemiplegia: a review. Int Rehab Med 1984;6:186-190.

5. Silver JR, Moulton A. The physiological and pathological sequelae of paralysis of the intercostal and abdominal muscles in tetraplegic patients. Paraplegia 1969;7:131-141.

6. Axen $\mathrm{K}$, Pineda $\mathrm{H}$, Shunfenthal $\mathrm{H}$, et al. Diaphragmatic function following cervical cord injury. Arch Phys Med Rehabilitation 1985;66:219-222.

7. Haas $\mathrm{F}$, Axen $\mathrm{K}$, Pineda $\mathrm{H}$, et al. Temporal pulmonary function changes in cervical cord injury. Arch Phys Med Rehabilitation 1985;66:138-144.

8. Guttman L, Silver J. Electromyographic studies on reflex activity of the intercostal and abdominal muscles in cervical cord lesions. Paraplegia 1965;3:1.

9. De Troyer A, Estenne M, Heilporn A. Mechanism of an active expiration in tetraplegic subjects. $N$ Engl J Med 1986;314(12):740-744.

10. De Troyer A, Estenne M, Vincken. Rib cage motion and muscle use in high tetraplegics. Am Rev Resp Dis 1986;133:1115-1119.

11. Goldman JM, Rose LS, Morgan MDL, et al. Measurement of abdominal wall compliance in normal subjects and tetra-plegic patients. Thorax 1986;41:513-518.

12. Estenne M, De Troyer A. Mechanism of the postural dependence of vital capacity in tetraplegic subjects. Am Rev Respir Dis 1987;135:367-371.

13. Leith DE, Bradley M. Ventilatory muscle strength and endurance training. J Appl Physio 1976;41(4):508-516.

14. Gross D, Ladd WH, Riley EJ, et al. The effect of training on strength and endurance of the diaphragm in quadriplegia. Am J Med 1980;68:27-35.

15. Brownlee S, Williams SJ. Physiotherapy in the respiratory care of patients with high spinal injury. Physiotherapy 1987;73(3):148-152.

16. Silver JR. Immediate management of spinal injuries. $\mathrm{Br} J$ Hosp Med 1983;29:412-425.

17. Stover SL, Fine PR. The epidemiology and economics of spinal cord injury. Paraplegia 1987;25:225-228.

\section{Reviewer's Note}

This article covers an interesting topic. The results are not conclusive however, because of the small sample size. A larger number of subjects showing a consistent increase in EMG activity would give more credibility to the conclusions drawn.

As the subjects used in this study would have some action of the diaphragm, other tests could also have been done. Firstly, a measure of the peak expiratory flow rates in the subjects may have been useful. Secondly, the ratio of FEV1 to FVC would be valuable in this respect, and would serve to control nuisance variables such as sex, age range etc.

\section{MANIPULATIVE THERAPISTS GROUP}

\section{ORTHOPAEDIC MANIPULATIVE THERAPY 1}

The Southern Transvaal branch of the MTG will be running the above course between January 1994 and Sept/Oct 1994. The course will be held over six "weekend" modules of 2-3 days each.

Venue: Johannesburg Hospital

Cost: R1,800. Deposit R300

Applicants:

- Must be members of the SASP and MTG

- Must be working in a situation where this concept can be used

- Must write the examination.

Closing Date for Application: 15 July 1993.

This early date is to enable successful candidates to make a start on the required reading for the course.

Applications forms are available from Judy Hahn, P O Box 72430, Parkview 2122. Tel. (011) 646-0797.

Enquiries about course content: Helen David - Course Leader Tel. (011) 783-5560 am.

\section{COURSE CONTENT}

This is a post-graduate course run by the Manipulative Therapists group of the South African Society of Physiotherapy. It is run part-time over a year in several Modules with the time between Modules to consolidate and put into clinical practise the work which has been taught.

Course Content: 120 hours including:

Theory related to the Maitland Concept of assessment and treatment of the spine and peripheral joints. Anatomy, physiology, radiology and clinical syndromes relevant to the spine and selected peripheral joints.

Practical techniques according to the books by GD Maitland relevant to the cervical, thoracic and lumbar spine, the sacroiliac joint and the shoulder and hip joints. Mobilisation and manipulation techniques.

Clinically supervised work. In addition, students prepare the following:

- Summaries of 100 prescribed articles.

- A project of approximately 2000 words.

- There is a National Examination consisting of

- 3 hour theory paper

- Practical techniques exam.

- 1 hour clinical exam.

- Project

A candidate must pass all parts of this exam with a $60 \%$ minimum. A certificate is issued by the National Manipulative Therapists Group.

\section{ERRATUM}

Professional Board for Physiotherapy

In Physiotherapy, November 1992, Volume 48 No 4 page 63 it was stated that Margaret Anne Beattie completed her MBA studies at the Pretoria University. This is an editorial error and should have read "Commenced her MBA studies at the Pretoria University". Any misrepresentation of the facts was unintentional.

The Editor 